\title{
Circulating tumour cell-derived plastin3 is a novel marker for predicting long-term prognosis in patients with breast cancer
}

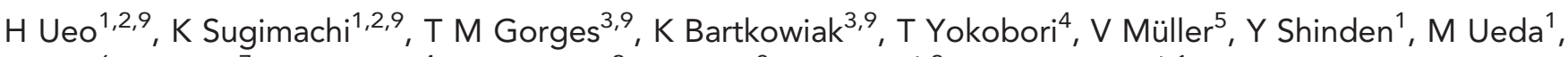

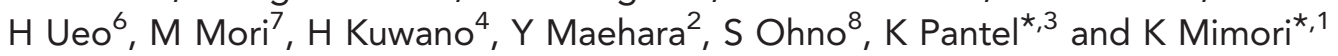

${ }^{1}$ Department of Surgery, Kyushu University Beppu Hospital, 4546 Tsurumihara, Beppu 874-0838, Japan; ${ }^{2}$ Department of Surgery and Science, Graduate School of Medical Sciences, Kyushu University, 3-1-1 Maidashi, Higashi-ku, Fukuoka 812-8582, Japan; ${ }^{3}$ Department of Tumor Biology, University Medical Center Hamburg-Eppendorf, Martinistrasse 52, D-20246 Hamburg, Germany; ${ }^{4}$ Department of General Surgical Science, Graduate School of Medicine, Gunma University, 3-39-22 Showamachi, Maebashi 371-0034, Japan; ${ }^{5}$ Department of Gynecology, University Medical Center Hamburg-Eppendorf, Martinistrasse 52, D-20246 Hamburg, Germany; ${ }^{6}$ Department of Surgery, Ueo Breast Surgical Hospital, 188-2 Haya, Oita 870-0854, Japan; ${ }^{7}$ Department of Gastroenterological Surgery, Graduate School of Medicine, Osaka University, Suita 565-0871, Japan and ${ }^{8}$ Department of Breast Oncology, Kyushu Cancer Center, 3-1-1 Notame, Minami-ku, Fukuoka 811-1347, Japan

Background: Identification of promising biomarkers that predict the prognosis of patients with breast cancer is needed. In this study, we hypothesised that the expression of the epithelial-mesenchymal transition-related biomarker plastin3 (PLS3) in peripheral blood could be a prognostic factor in breast cancer.

Methods: We examined PLS3 expression in breast cancer cell lines with epithelial and mesenchymal traits and in circulating tumour cells (CTCs) obtained from the peripheral blood of breast cancer patients. We investigated PLS3 expression in the peripheral blood of 594 patients with breast cancer to evaluate the clinical significance of PLS3 expression.

Results: Robust PLS3 expression was observed in different breast cancer cell lines (Hs578t, MCF-7, MDA-MB-468, and MDA-MB231) as well as in a bone marrow derived cancer cell line (BC-M1). In both the training $(n=298)$ and validation $(n=296)$ sets, PLS3 expression was observed in CTCs of patients with breast cancer. PLS3-positive patients showed significantly poorer overall and disease-free survival than $P L S 3$-negative patients ( $P=0.0001$ and 0.003 , respectively). Subset analysis revealed that this prognostic biomarker was relevant in patients with stage I-III cancer, particularly in patients with luminal-type and triple-negative-type tumours.

Conclusions: These data demonstrated that PLS3 was expressed in CTCs undergoing the epithelial-mesenchymal transition in patients with breast cancer. Furthermore, PLS3 may be an excellent biomarker for identifying groups at risk of recurrence or with a poor prognosis.

Circulating tumour cells (CTCs) are commonly detected by epithelial markers of cancer cells, such as EpCAM or cytokeratins (CK) (Pantel et al, 2008). CTCs have been identified in the peripheral blood $(\mathrm{PB})$ of patients with gastric, colorectal, and breast cancers using multiple epithelial cell-specific markers, for example, CEA, CK-7, and CK-19 (Mori et al, 1998, 2002; Mimori et al, 2008a,b). However, some CTCs may gain mesenchymal properties through the epithelial-to-mesenchymal transition (EMT), in which the degree of epithelial differentiation is reduced and the expression of mesenchymal genes is induced (Kang and

\footnotetext{
*Correspondence: Professor K Pantel; E-mail: tumorbiologie@uke.uni-hamburg.de or Professor K Mimori; E-mail: kmimori@beppu.kyushu-u.ac.jp ${ }^{9}$ These authors contributed equally to this work.
} 
Pantel, 2013). Therefore, detection of tumour cells that have undergone EMT-like changes is hampered when targeting only epithelial marker proteins, leading to false-negative findings. Tumour cells that have undergone EMT-associated changes are able to acquire invasive properties or stem-like characteristics (Polyak and Weinberg, 2009). Moreover, cancer cells with a fully completed EMT may not be able to form metastases, whereas tumour cells with an intermediate E/M phenotype appear to be the initiators of metastases (Tam and Weinberg, 2013). Hence, the discovery of new marker proteins for CTCs with both epithelial and mesenchymal attributes is essential for the identification of a true marker for CTCs with metastatic potential.

Plastin3 (PLS3) is a novel CTC marker in colon cancer and is expressed on tumour cells with epithelial and EMT-associated phenotypes (Yokobori et al, 2013; Sugimachi et al, 2014). PLS3 encodes for an actin-bundling protein that may be important for processes enabling tumour cells to form metastases, such as the escape from anoikis, resistance to chemotherapy, increased cancer stemness, and induction of EMT (Yokobori et al, 2013).

In the current study, we investigated whether PLS3 was a suitable marker for CTCs and for predicting prognosis in breast cancer. Our data supported the clinical significance of PLS3 as marker for poor prognosis in lymph node-negative and triplenegative breast cancer cases, emphasising the importance of this molecule.

\section{MATERIALS AND METHODS}

Cultivation of cell lines. MDA-MB-231 cells were maintained in Dulbecco's modified Eagle's medium supplemented with $10 \%$ fetal calf serum and $2 \mathrm{mM}$ L-glutamine (Gibco/Life Technologies, Carlsbad, CA, USA) in a humidified atmosphere at $37^{\circ} \mathrm{C}$ and $10 \% \mathrm{CO}_{2}$. All other cells were cultivated as described previously (Bartkowiak et al, 2009).

Qualitative reverse transcription-PCR (qRT-PCR). RNA was isolated using a NucleoSpin RNA II Kit (Macherey-Nagel, Düren, Germany) followed by cDNA synthesis (First Strand cDNA Synthesis Kit, Thermo Scientific, Waltham, MA, USA). Primers were designed and $\mathrm{qRT}-\mathrm{PCR}$ was performed as described elsewhere (Yokobori et al, 2013).

Sample procurement for western blotting. Cells were washed with PBS and lysed in lysis mix (9.8 $\mathrm{m}$ urea, $15 \mathrm{~mm}$ EDTA, and $30 \mathrm{~mm}$ Tris). Cell lysates were homogenised and supernatants were then collected. Negative controls (FICOLL-enriched peripheral blood mononuclear cells (PBMCs) from healthy individuals) were isolated to test the specificity of PLS3. Protein was purified by precipitation using $600 \mu \mathrm{l}$ precipitant (component of the 2-D Quant Kit, GE Healthcare, Uppsala, Sweden) per $250 \mu$ l sample and coprecipitant (component of the 2-D Quant Kit) in the same amount. Purified proteins were dissolved in $100 \mu \mathrm{l}$ of $9.8 \mathrm{M}$ urea and solubilised for $1 \mathrm{~h}$ at room temperature. Protein concentrations were determined using a Pierce BCA Protein Assay Kit (Pierce, Rockford, MD, USA) following the manufacturer's instructions, with BSA as standard.

Western blotting. Protein samples were separated by sodium dodecyl sulfate-polyacrylamide gel electrophoresis using $10 \%$ polyacrylamide gels. For all analyses, $40 \mu \mathrm{g}$ of protein was applied. Proteins were transferred to Immobilon-PSQ membranes (Millipore $\mathrm{GmbH}$, Schwalbach, Germany), and nonspecific binding was blocked by incubation in 5\% low-fat powdered milk (Roth, Karlsruhe, Germany) in TBST (blocking buffer) with gentle agitation for $1 \mathrm{~h}$. Primary antibodies (rabbit polyclonal anti-PLS3, C15, Santa Cruz Biotechnology, Santa Cruz, CA, USA, 1:1000; rabbit monoclonal anti- $\alpha$-tubulin, Cell Signaling Technology,
Danvers, MA, USA, 1:10000) were diluted in blocking buffer and incubated with the membrane at $4{ }^{\circ} \mathrm{C}$ overnight. Membranes were incubated with horseradish peroxidase-conjugated secondary antibodies (Dako, Glostrup, Denmark) diluted 1:1500 in blocking buffer. Bands were visualised using ECL Prime Western Blotting Detection Reagent and X-ray films (GE Healthcare). X-ray films were digitised using a GS-700 imaging densitometer (Bio-Rad, Hercules, CA, USA). Densitometric analysis was performed using Quantity One software (Bio-Rad). Each reaction was performed in biological triplicate.

Cell staining (spiking experiments). Cancer cells were spiked into blood from healthy individuals, followed by FICOLL density centrifugation and cytospin preparation (Superfrost Plus, Karl Hecht KG, Sondheim, Germany). The slides were air-dried overnight and stored at $-80{ }^{\circ} \mathrm{C}$ until processing. Immunocytochemical double staining was performed using anti-pan cytokeratin (panCK) antibodies (AE1/AE3, Dako) together with two different anti-PLS3 antibodies (C15, Santa Cruz Biotechnology (Plastin antibody 1) or PA5-27883, Thermo Scientific (Plastin antibody 2)). Briefly, slides were thawed $30 \mathrm{~min}$ before incubation with $4 \%$ PFA in PBS. After washing with PBS, cells were permeabilised using $1 \%$ Triton X-100 in PBS. Blocking of unspecific binding was performed after two washing steps using 10\% AB-Serum (Biotest, Dreieich, Germany) in PBS. Anti-PLS3 antibodies were then added at a dilution of $1: 100(10 \%$ AB-Serum in PBS) and incubated for 45 min. Subsequently, slides were washed with PBS, and Alexa546 goat anti-rabbit secondary antibodies (Molecular Probes, Eugene, OR, USA) were applied for $45 \mathrm{~min}$ (diluted 1:200 in 10\% ABSerum in PBS). After further washing steps, the panCK cocktail (AE1/AE3) was applied $(1: 300)$ and incubated for $45 \mathrm{~min}$, followed by additional washing steps. Slides were covered with Vectashield Mounting Medium containing DAPI (Vector Laboratories, Burlingame, CA, USA).

Staining controls were run in parallel using dilution media instead of the primary and secondary antibodies. Slides were evaluated manually using an Axioplan 2 microscope (Carl Zeiss AG, Oberkochen, Germany).

PB samples from breast cancer cases and healthy controls. A total of 594 patients with breast cancer underwent resection of the primary tumour at the Kyushu University Beppu Hospital, Kyushu Cancer Center or affiliated hospitals from 2000 to 2008. The average age of the patients was 55.2 years, and tumour stages I, II, III, and IV were observed $(34.1 \%, 58.2 \%, 6.2 \%$, and $1.5 \%$, respectively). Of the patients, $39.3 \%$ were positive for lymph node metastases and $1.5 \%$ were positive for distant metastases (Table 1). PB sample sets were used to clarify the prognostic value of PLS3 as a novel marker for CTCs. As a training set, 298 PB samples were obtained before surgery (average age 56.3 years). Oestrogen receptor (ER), progesterone receptor (PgR), and HER2 were examined using usual immunohistochemical methods. Subtypes were defined as follows: luminal A, ER and/or PgR ( +), HER2 ( - ); luminal $\mathrm{B}, \mathrm{ER}$ and/or $\operatorname{PgR}(+)$, HER2 $(+)$; HER2 type, ER $(-), \operatorname{PgR}(-), \operatorname{HER} 2(+)$; triple negative, ER $(-), \operatorname{PgR}(-)$, HER2 ( - ); unclassified type, others (Nguyen et al, 2008). Luminal A, luminal B, HER2 type, triple-negative type, and unclassified tumour type were positive in $72.9 \%, 4.7 \%, 8.0 \%, 9.7 \%$, and $4.7 \%$ of patients, respectively. In addition, 296 patient-derived blood samples were tested as a validation set (average age 55.2 years), with tumour-type distributions as follows: luminal A, 67.2\%; luminal B, 8.4\%; HER2 type, 5.1\%; triple-negative type, $15.2 \%$; and unclassified, $4.1 \%$. Patients with stage I-III cancer were evaluated for tumour recurrence by physical examination, and tumour marker testing (CEA and CA15-3) was conducted every 3 months for 3 years and every 6 months for 5 years thereafter. To evaluate disease recurrence, computed tomography or magnetic resonance imaging was applied every 6-12 weeks for 3 years and then every 
Table 1. Relationship between peripheral blood PLS3 expression and clinicopathologic factors in breast cancer patients

\begin{tabular}{|c|c|c|c|c|c|}
\hline \multirow[b]{2}{*}{ Variables } & \multicolumn{2}{|c|}{$\begin{array}{l}\text { PLS3 negative } \\
\quad(n=205)\end{array}$} & \multicolumn{2}{|c|}{$\begin{array}{l}\text { PLS3 positive } \\
(n=389)\end{array}$} & \multirow[b]{2}{*}{$P$-value } \\
\hline & $n$ & $\%$ & $n$ & $\%$ & \\
\hline Age (years, mean) & 55.7 & & 55.2 & & 0.57 \\
\hline \multicolumn{6}{|l|}{$\mathrm{T}$ classification } \\
\hline $\begin{array}{l}\text { T1 } \\
\text { T2 } \\
\text { T3 } \\
\text { T4 }\end{array}$ & $\begin{array}{c}91 \\
101 \\
10 \\
3\end{array}$ & $\begin{array}{l}31.7 \\
38.7 \\
25.6 \\
42.9\end{array}$ & $\begin{array}{c}196 \\
160 \\
29 \\
4\end{array}$ & $\begin{array}{l}68.3 \\
61.3 \\
74.4 \\
57.1\end{array}$ & 0.18 \\
\hline \multicolumn{6}{|c|}{ Lymph node metastasis } \\
\hline $\begin{array}{l}\text { Negative } \\
\text { Positive }\end{array}$ & $\begin{array}{c}133 \\
72\end{array}$ & $\begin{array}{l}36.8 \\
30.9\end{array}$ & $\begin{array}{l}228 \\
161\end{array}$ & $\begin{array}{l}63.2 \\
69.1\end{array}$ & 0.13 \\
\hline \multicolumn{6}{|c|}{ Venous invasion } \\
\hline $\begin{array}{l}\text { Negative } \\
\text { Positive }\end{array}$ & $\begin{array}{c}11 \\
194\end{array}$ & $\begin{array}{l}31.4 \\
34.7\end{array}$ & $\begin{array}{c}24 \\
365\end{array}$ & $\begin{array}{l}68.6 \\
65.3\end{array}$ & 0.69 \\
\hline \multicolumn{6}{|c|}{ Lymphatics invasion } \\
\hline $\begin{array}{l}\text { Negative } \\
\text { Positive }\end{array}$ & $\begin{array}{c}74 \\
131\end{array}$ & $\begin{array}{l}32.5 \\
35.8\end{array}$ & $\begin{array}{l}154 \\
235\end{array}$ & $\begin{array}{l}67.5 \\
64.2\end{array}$ & 0.4 \\
\hline \multicolumn{6}{|c|}{ Distant metastasis } \\
\hline $\begin{array}{l}\text { Negative } \\
\text { Positive }\end{array}$ & $\begin{array}{c}204 \\
1\end{array}$ & $\begin{array}{l}34.9 \\
11.1\end{array}$ & $\begin{array}{c}381 \\
8\end{array}$ & $\begin{array}{l}65.1 \\
88.9\end{array}$ & 0.1 \\
\hline \multicolumn{6}{|l|}{ Nuclear grade ${ }^{a}$} \\
\hline $\begin{array}{l}\text { Grade1-2 } \\
\text { Grade3 }\end{array}$ & $\begin{array}{c}146 \\
54\end{array}$ & $\begin{array}{l}36.1 \\
32.7\end{array}$ & $\begin{array}{l}258 \\
111\end{array}$ & $\begin{array}{l}63.9 \\
67.3\end{array}$ & 0.44 \\
\hline \multicolumn{6}{|l|}{ Serum CEA ${ }^{b}$} \\
\hline $\begin{array}{l}\leqq 5 \mathrm{ng} \mathrm{ml}^{-1} \\
>5 \mathrm{ng} \mathrm{ml}^{-1}\end{array}$ & $\begin{array}{c}187 \\
8\end{array}$ & $\begin{array}{l}35.2 \\
27.6\end{array}$ & $\begin{array}{c}345 \\
21\end{array}$ & $\begin{array}{l}64.8 \\
72.4\end{array}$ & 0.67 \\
\hline \multicolumn{6}{|l|}{ Serum CA15-3 ${ }^{c}$} \\
\hline $\begin{array}{l}\leqq 30 \mathrm{Uml}^{-1} \\
>30 \mathrm{Uml}^{-1}\end{array}$ & $\begin{array}{c}186 \\
8\end{array}$ & $\begin{array}{l}35.2 \\
33.3\end{array}$ & $\begin{array}{c}342 \\
16\end{array}$ & $\begin{array}{l}64.8 \\
66.7\end{array}$ & 0.85 \\
\hline \multicolumn{6}{|c|}{ Adjuvant chemotherapy } \\
\hline $\begin{array}{l}(-) \\
(+)\end{array}$ & $\begin{array}{c}90 \\
115\end{array}$ & $\begin{array}{l}33.5 \\
35.4\end{array}$ & $\begin{array}{l}179 \\
210\end{array}$ & $\begin{array}{l}66.5 \\
64.6\end{array}$ & 0.69 \\
\hline \multicolumn{6}{|c|}{ Oestrogen receptor ${ }^{d}$} \\
\hline $\begin{array}{l}\text { Negative } \\
\text { Positive }\end{array}$ & $\begin{array}{c}52 \\
153 \\
\end{array}$ & $\begin{array}{l}32.7 \\
35.6 \\
\end{array}$ & $\begin{array}{l}107 \\
277\end{array}$ & $\begin{array}{l}67.3 \\
64.4 \\
\end{array}$ & 0.096 \\
\hline \multicolumn{6}{|c|}{ Progesteron receptor ${ }^{e}$} \\
\hline $\begin{array}{l}\text { Negative } \\
\text { Positive }\end{array}$ & $\begin{array}{c}55 \\
143\end{array}$ & $\begin{array}{l}24.0 \\
40.6\end{array}$ & $\begin{array}{l}174 \\
209\end{array}$ & $\begin{array}{l}76.0 \\
59.4\end{array}$ & 0.0008 \\
\hline \multicolumn{6}{|c|}{ HER2/neu expression $^{f}$} \\
\hline $\begin{array}{l}0 \text { to } 2+ \\
3+\end{array}$ & $\begin{array}{l}125 \\
35\end{array}$ & $\begin{array}{l}30.2 \\
44.9\end{array}$ & $\begin{array}{c}289 \\
43\end{array}$ & $\begin{array}{l}69.8 \\
55.1\end{array}$ & 0.0313 \\
\hline \multicolumn{6}{|l|}{ Subtype $^{g}$} \\
\hline $\begin{array}{l}\text { Luminal A } \\
\text { Luminal B } \\
\text { HER2 } \\
\text { Triple negative } \\
\text { Not determined }\end{array}$ & $\begin{array}{c}147 \\
19 \\
16 \\
19 \\
4\end{array}$ & $\begin{array}{l}35.3 \\
48.7 \\
42.1 \\
26.0 \\
20.0\end{array}$ & $\begin{array}{l}270 \\
20 \\
22 \\
54 \\
16\end{array}$ & $\begin{array}{l}64.7 \\
51.3 \\
57.9 \\
74.0 \\
80.0\end{array}$ & 0.066 \\
\hline \multicolumn{6}{|c|}{ Anti-hormone therapy } \\
\hline $\begin{array}{l}(-) \\
(+)\end{array}$ & $\begin{array}{c}55 \\
150 \\
\end{array}$ & $\begin{array}{l}27.6 \\
38.0 \\
\end{array}$ & $\begin{array}{l}144 \\
245 \\
\end{array}$ & $\begin{array}{l}72.4 \\
62.0 \\
\end{array}$ & 0.012 \\
\hline \multicolumn{6}{|c|}{ The site of recurrence } \\
\hline $\begin{array}{l}\text { Bone metastasis } \\
\text { Lung metastasis } \\
\text { Local recurrence } \\
\text { Liver metastasis } \\
\text { Others }\end{array}$ & $\begin{array}{l}5 \\
3 \\
2 \\
1 \\
2\end{array}$ & $\begin{array}{r}35.7 \\
18.8 \\
18.2 \\
10.0 \\
6.7\end{array}$ & $\begin{array}{c}9 \\
13 \\
9 \\
9 \\
28\end{array}$ & $\begin{array}{l}64.3 \\
81.3 \\
81.8 \\
90.0 \\
93.3\end{array}$ & 0.0018 \\
\hline \multicolumn{6}{|l|}{ Cause of death } \\
\hline $\begin{array}{l}\text { Cancer death } \\
\text { Non-cancer death }\end{array}$ & $\begin{array}{l}4 \\
1 \\
\end{array}$ & $\begin{array}{l}10.5 \\
50.0 \\
\end{array}$ & $\begin{array}{c}34 \\
1 \\
\end{array}$ & $\begin{array}{l}89.5 \\
50.0 \\
\end{array}$ & 0.18 \\
\hline \multicolumn{6}{|c|}{$\begin{array}{l}\text { Abbreviations: CA15-3= cancer antigen 15-3; } \\
\text { human epidermal growth factor receptor 2; PLS } \\
\mathbf{a}_{\text {Information of } 25 \text { patients was not available. }} \\
\mathbf{b}_{\text {Information of } 33 \text { patients was not available. }} \\
\mathbf{c}_{\text {Information of } 42 \text { patients was not available. }} \\
\mathbf{d}_{\text {Information of } 5 \text { patients was not available. }} \\
\mathbf{e}_{\text {Information of } 13 \text { patients was not available. }} \\
\mathbf{f}_{\text {Information of } 102 \text { patients was not available. }} \\
\mathbf{g}_{\text {Information of } 7 \text { patients was not available. }}\end{array}$} \\
\hline
\end{tabular}

6 months for up to 5 years after surgery. Postoperative adjuvant therapy was applied based on the international consensus (Goldhirsch et al, 2005). Hormonal monotherapy was done on the low-risk patients with ER and/or $\operatorname{PgR}(+)$. Adjuvant chemotherapy was added on high-risk patients. Recurrence was determined by imaging or pathological diagnosis of biopsy samples. PB samples from healthy individuals $(n=25)$ who had no evidence of any disease by physical examination, blood tests, $\mathrm{X}$-ray, or ultrasound examination were used as a control set. All processed samples were used in accordance with institutional guidelines after obtaining written informed consent from the participants. Postoperative follow-up was performed following the guidelines published by the Japanese Society for Breast Cancer.

Quantitative RT-PCR for PB samples. Total RNA was extracted from PB of patients using a PAXgene Blood RNA Kit (Qiagen, Venlo, Netherlands), as previously described (Iwaya et al, 2013). Gene-specific oligonucleotide primers were designed and qRTPCR was performed in a LightCycler (Roche Diagnostics, Basel, Switzerland) using the LightCycler-FastStart DNA Master SYBR Green I Kit, as described (Iwaya et al, 2013).

Statistical analysis. The sample sizes of the training and validation sets were calculated using SAS statistics software v. 10 (SAS Institute, Cary, NC, USA) based on the results of a smallscale test $(n=50)$ in which a one-sided $P$-value of 0.025 would have $80 \%$ power to detect a difference between the disease-free survival (DFS) and overall survival (OS) curves of patients with and without CTCs. The relationships between the OS rate, DFS rate, and PLS3 expression were analysed by Kaplan-Meier survival curves and log-rank tests. Cox proportional-hazard regression was used to determine multivariate hazard ratios for the OS and DFS rates. The comparison of clinicopathological factors was analysed using Student's $t$-tests, $\chi^{2}$-tests, and analysis of variance. All $P$-values were two-sided, and differences were considered significant when $P$-values were $<0.05$. Data were analysed using JMP software v. 10 (SAS Inst. Inc.).

\section{RESULTS}

Differential expression of PLS3 in breast cancer cells and blood cells. First, we examined PLS3/PLS3 expression in a set of different breast cancer cell lines using western blotting or qRT-PCR (Figure 1A-D). We also included BC-M1 cells as a DTC cell line derived from the bone marrow of a breast cancer patient, which served as a model for disseminating breast cancer cells (Bartkowiak et al, 2010). Samples from healthy individuals were used to the specificity of our marker.

PLS3 protein as well as PLS3 transcripts were detectable in MDA-MB-231 (E/M phenotype) and Hs578t cells (mesenchymal phenotype; Bartkowiak et al, 2009, 2010) as well as MCF-7 (luminal phenotype) and MDA-MB-468 (basal phenotype; Bartkowiak et al, 2009, 2010 cells (Figure 1A-D). Interestingly, very high levels of PLS3 were detected in BC-M1 cells. Thus, PLS3 was expressed in breast cancer cells of different origins and at various stages of the EMT, indicating that PLS3 may be a suitable marker for detecting breast cancer cells.

To assess the specificity of PLS3 as a CTC marker, we analysed its expression in PBMCs from healthy controls (Figure 1C). PLS3 expression in these cells was below our detection limit in the PBMC fraction. These findings were confirmed by analysing PLS3 mRNA expression in PBMCs of healthy individuals (Figure 1D).

Next, we simulated the detection of different CTC subpopulations by immunocytochemistry. For this aim, PB samples from healthy individuals were spiked with breast cancer cells of the MDA-MB-468, SKBR3, and BC-M1 cell lines. Pure blood was used as negative control. We could detect fluorescence signals for PLS3 

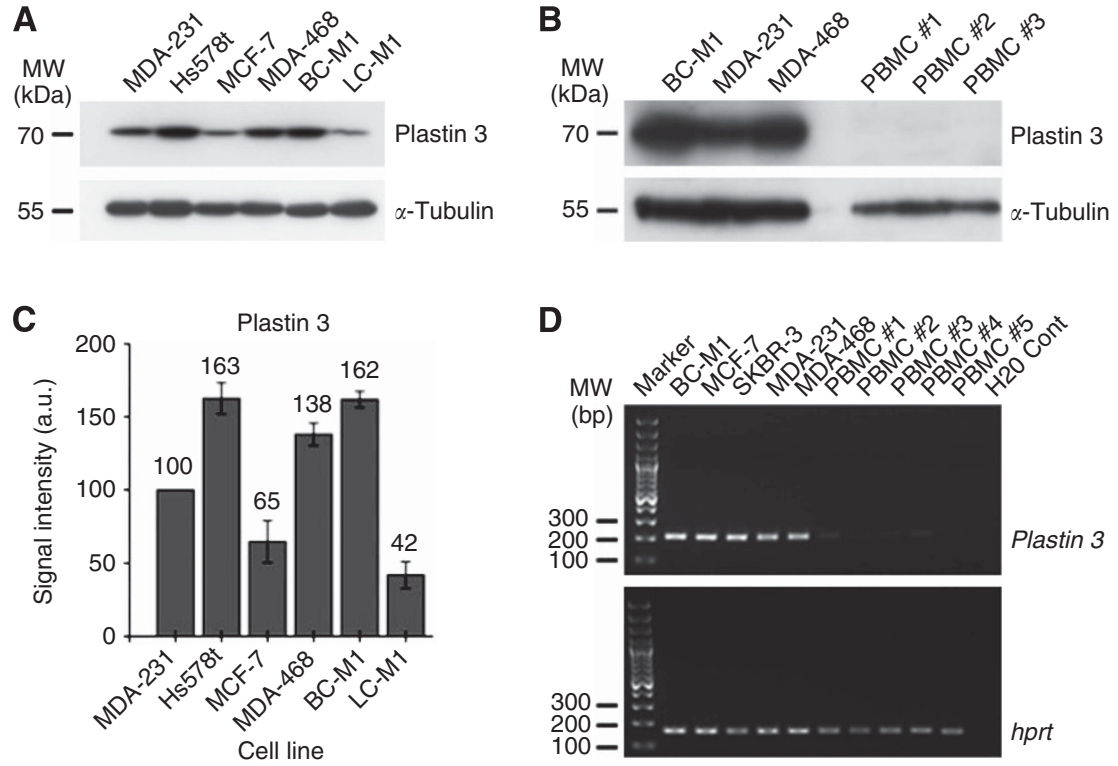

Figure 1. Analysis of PLS3 protein and mRNA levels. (A) Comparison of PLS3 expression in breast cancer cell lines from primary tumours and a DTC cell line from the bone marrow of patients with breast cancer (BC-M1). The lung cancer DTC cell line LC-M1 served as an additional reference for a tumour cell population from a distant site. $\alpha$-Tubulin served as a loading control. (B) Quantitative western blot analysis of PLS3 expression in the indicated cell lines. The dimensionless signal intensities are the average of three independent experiments (given as numbers), and vertical error bars indicate s.d. The signal intensities were normalised to the expression of $\alpha$-tubulin. (C) Analysis of PLS3 expression in PBMCs from three different healthy control individuals by western blot. The breast cancer cell lines served as a reference for PLS3 expression in breast cancer cells, and $\alpha$-tubulin served as a loading control. We observed lower signal intensities for $\alpha$-tubulin in PBMCs than in the other cell lines. Hence, X-ray films with prolonged exposition times are presented to substantiate that PLS3 expression was below the detection limit in PBMCs. (D) Comparison of PLS3 gene expression between breast cancer cell lines and PBMCs of five different healthy control individuals. Analysis of the housekeeping gene hprt confirmed that the analyses for PLS3 provided comparable results between the breast cancer cell lines and the PBMCs. The water control was designated as H20 Cont. Unlike for PLS3 protein, weak signals for PLS3 mRNA were detected in PBMCs. MDA-231, MDA-MB-231 cells; MDA-468, MDA-MB-468 cells. All experiments: $n=3$.

in all tested cell lines (Figure 2A). Interestingly, specific signals for PLS3 were observable around the nucleus and in the cytoplasm. Although infrequently, weak signals were rarely detectable that did not belong to the spiked tumour cells (Figure 2B). In the case of BC-M1 cells, large PLS3-positive cells were detected, which were not observed in unspiked blood samples. Thus, tumour cells were clearly distinguishable from normal blood cells according to differences in PLS3/PLS3 expression.

Incidence of PLS3-positive CTCs in PB of breast cancer patients. On the basis of our findings and our previous study in colorectal cancer (10), we determined the level of PLS3 mRNA by qRT-PCR in PB samples as a marker for the presence of CTCs. The cutoff values of PLS3 were determined by receiver operating characteristic (ROC) curves, which were constructed by plotting all possible pairs in the training set. Sensitivities of PLS3 were calculated as the ratio of the number of patients with PCR evidence of PLS3 in PB divided by the number patients who had metastases. Specificities were calculated as the ratio of the number of patients without PCR evidence of PLS3 in PB divided by the number of patients who did not have metastases. ROC analysis and the optimal cutoff value were calculated as the PLS3 level that maximised the sensitivity/(1-specificity), as previously described (Yokobori et al, 2013).

From the 594 PB samples, 389 (65.5\%) breast cancer patients had PLS3-positive CTCs, whereas only 9 cases (1.5\%) had clinically evident metastatic lesions (Table 1). Subset analysis revealed that the frequency of PLS3-positive cases was significantly elevated in HER2-negative patients $(289 / 414,69.8 \%)$ compared with HER2positive patients $(43 / 78,55.1 \% ; P=0.0313$, Table 1$)$. Subset analyses also revealed that 174 of $229 \mathrm{PgR}$-negative patients
(76\%) exhibited PLS3-positive CTCs compared with 143 of 352 PgR-positive patients $(41.0 \%, P=0.0008)$, while the correlation to the ER status was not significant $(P=0.096)$. Notably, $74 \%$ (54 of 73 patients) of the triple-negative cohort showed PLS3-positive CTCs compared with $182(37.3 \%)$ of 488 patients belonging to other breast cancer subtypes $(P=0.023)$.

Prognostic relevance of PLS3-positive CTCs. PB samples were analysed to elucidate the prognostic value of PLS3 in breast cancer. We divided samples into training and validation sets in order to perform a cross-validation. Two independent studies comprising 298 patients in the test set and 296 patients in the validation set were performed (total samples $n=594$ ) in order to assess the reproducibility of our results. Breast cancer patients in both the training set and the validation set presenting positive PLS3 values had a significantly poorer OS rate than patients with negative values (Figure $3 \mathrm{~A}$ and $\mathrm{B}$ ). In patients without synchronous distant metastasis (TNM stages I-III), those with PLS3-positive CTCs in the PB further indicated significantly shorter DFS rates than patients with PLS3-negative CTCs in both the training and validation sets (Figure $3 \mathrm{C}$ and $\mathrm{D}$ ). The influence of PLS3 expression on OS $(P=0.0001)$ and DFS $(P=0.0003)$ was also shown in all combined test patients $(n=594$; Figure $3 \mathrm{E}$ and F). In 361 breast cancer cases without lymph node metastasis, PLS3positive patients showed significantly poorer OS and DFS than PLS3-negative individuals (Figure 3G and H). Multivariate analysis revealed that PLS3 expression in the $\mathrm{PB}$ was independently associated with poor OS (hazard ratio $(\mathrm{HR})=4.34, P=0.0023$ ) and DFS $(\mathrm{HR}=2.67, P=0.0013$; Table 2$)$.

Prognostic relevance of PLS3-positive CTCs in breast cancer subtypes. Finally, we analysed the long-term prognosis of patients 
A

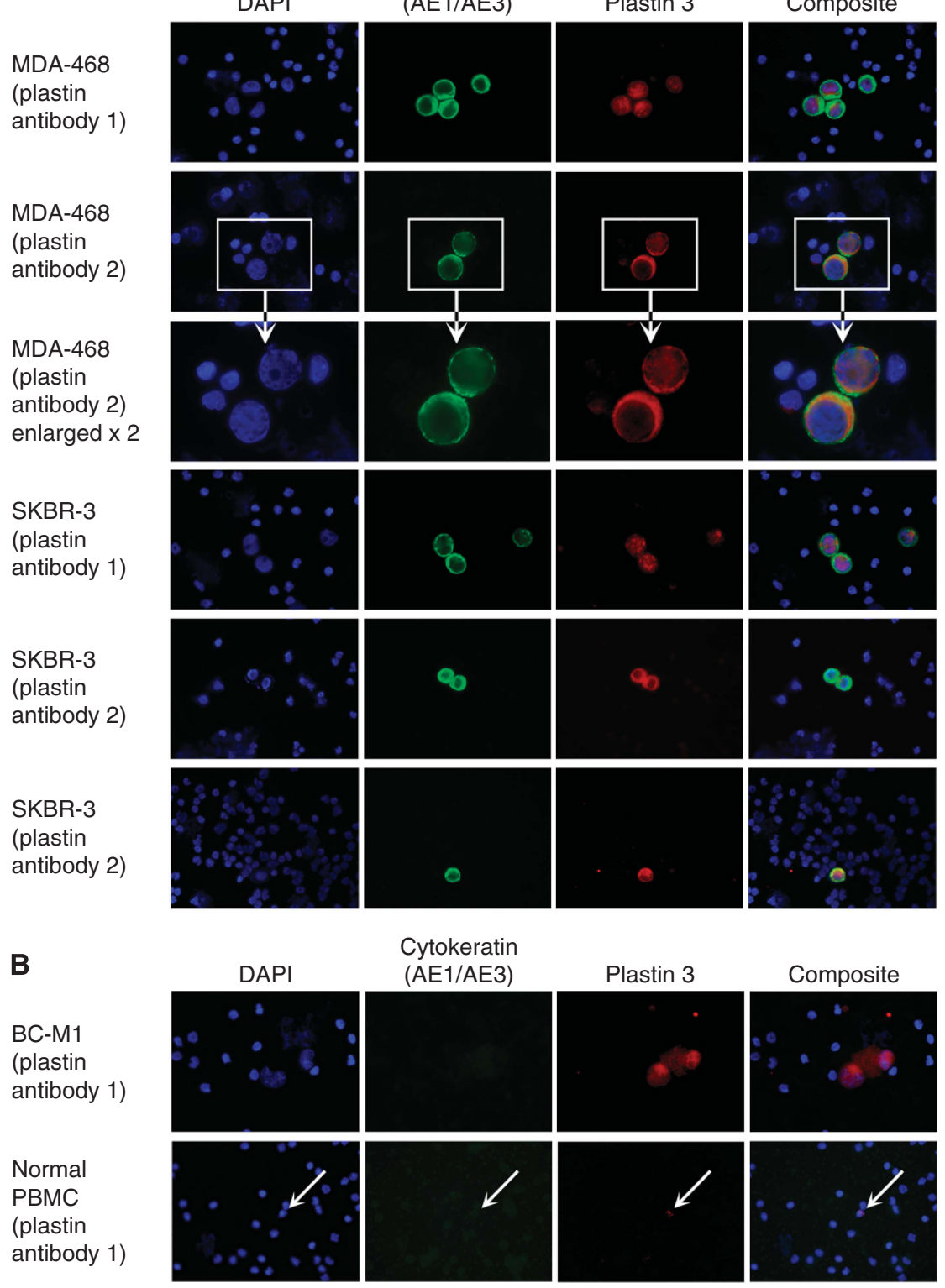

Figure 2. Comparison of PLS3 expression in breast cancer cell lines with PLS3 expression in peripheral blood mononuclear cells of healthy control individuals by immunocytochemical double staining. Cells of the assigned cell lines were spiked in the blood samples. Identification of the tumour cells was supported by the cytokeratin-specific antibody AE1/AE3. Nuclei were stained with DAPI, and the composite image is an overlay of the DAPI, cytokeratin, and PLS3 images. Two different PLS3 antibodies were applied for the analysis. (A) For MDA-MB-468 (MDA-468), an enlarged view of stained cells is shown. (B) BC-M1 analysis for PLS3 and blood samples without cell spiking. PLS3 signals in PBMC were labelled with arrows.

with stages I-III breast cancer according to PLS3 expression and cancer subtype. Patients with luminal type B or triple-negative-type cancer with PLS3 expression had significantly poorer DFS (Supplementary Figure 1B and D). In terms of OS, PLS3 expression was significantly associated with poorer survival rates in patients with stages I-III luminal type A or triple-negative type cancer (Supplementary Figure 2A and D).

\section{DISCUSSION}

In the present study, we demonstrate that PLS3/PLS3 is a suitable novel marker for the identification of CTCs in breast cancer. In addition, PLS3-positive CTCs exhibited prognostic significance in a large training cohort of patients with sufficient follow-up, which was confirmed in an independent validation group. Subset analysis revealed that this new prognostic biomarker was particularly relevant in patients with luminal B and triple-negative subtypes of breast cancer (Li et al, 2009).

Interestingly, PLS3 expression was detectable at all stages of the EMT. This finding was confirmed by the analysis of CTCs from breast cancer patients, demonstrating that PLS3 was expressed in CTCs with different EMT stages, including the intermediate stage, which characterises cancer stem cells with a high plasticity (Yokobori et al, 2013). The specificity of PLS3 as a CTC marker was highlighted by the absence of mRNA and protein expression in PBMCs from healthy controls, therefore PLS3 mRNA is originated from breast cancer cells. As shown in Figure 2, PLS3 mostly localised in cytoplasm, but partial nuclear localisation was also observed in breast cancer cell lines. Partial PLS3 nuclear 

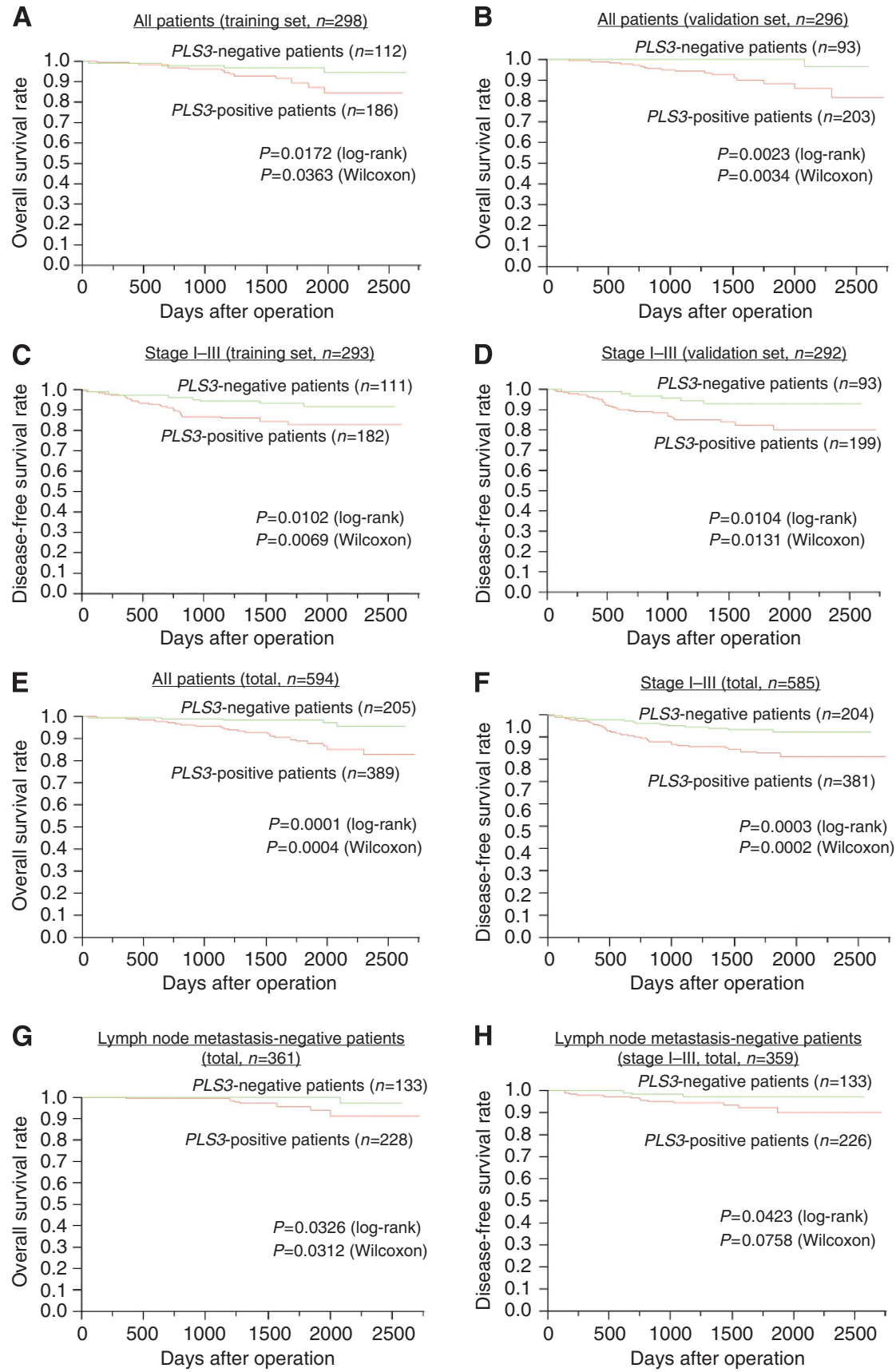

Figure 3. Prognostic significance of PLS3 expression in breast cancer cases. Comparison of the OS rate in 298 test sample sets (A) and 296 validation sets (B) from PLS3 $(+)$ and PLS3 $(-)$ breast cancer cases of all stages. Comparison of the DFS rate in 293 test sample sets (C) and 292 validation sets (D) from PLS3 (+) and PLS3 ( - ) breast cancer cases of stage I-III. In 594 patients (for the analysis of all stages), we compared OS rates between $P L S 3(+)$ and PLS3 $(-)$ cases $(\mathbf{E})$. DFS was compared in the 585 cases of stage I-III cancers $(P L S 3(+)$ vs PLS3 $(-)(\mathbf{F})$. OS was compared in 361 cases of all stages and DFS was compared in 359 cases of stages I-III; all cases did not have lymph node metastasis at the time of operation $(\mathbf{G}, \mathbf{H})$.

localisation was also confirmed in CTC from breast cancer patients (data not shown). As the clinical application of PLS3 as a marker protein was the focus of this work, the biology behind the nuclear localisation of PLS3 remains to be investigated in a future study.

According to our previous work (Kosaka et al, 2012), we used qRT-PCR as a high-throughput technology for the subsequent prognostic study of large patient cohorts. PLS3-positive CTCs were detected in $65.5 \%$ of all cases, and $98.5 \%$ of these patients were free of overt distant metastases (stages I-III). Compared with other breast cancer studies, this value is at the far upper end of the reported detection rates (Zhang et al, 2012). Unlike epithelial differentiation markers, such as CKs (Braun and Pantel, 2001), PLS3 was expressed at higher levels in all breast cancer subtypes and EMT phenotypes, which may explain the high CTC detection rate observed in this study.

For basal-like and triple-negative subtypes, tumour cell plasticity is of special relevance, as these types of cancers frequently undergo some part of the EMT (Jiang et al, 2011). Thus, the high detection rate of CTCs in patients with the basal-like or triple-negative phenotype, as demonstrated in the present study, deserves special attention. Using PLS3 as a CTC marker, we found that $74 \%$ of the triple-negative cases were considered to be positive for CTCs. 
Table 2. Univariate and multivariate analysis for survival of peripheral blood PLS3 status and clinicopathological factors in breast cancer patients $(n=591)$

\begin{tabular}{|c|c|c|c|c|c|c|c|c|}
\hline \multirow[b]{3}{*}{ Variables } & \multicolumn{4}{|c|}{ Disease-free survival } & \multicolumn{4}{|c|}{ Overall survival } \\
\hline & \multicolumn{2}{|c|}{ Univariate analysis } & \multicolumn{2}{|c|}{ Multivariate analysis } & \multicolumn{2}{|c|}{ Univariate analysis } & \multicolumn{2}{|c|}{ Multivariate analysis } \\
\hline & HR $(95 \% \mathrm{Cl})$ & $P$-value & $\mathrm{HR}(95 \% \mathrm{Cl})$ & $P$-value & $\operatorname{HR}(95 \% \mathrm{Cl})$ & $P$-value & $\mathrm{HR}(95 \% \mathrm{Cl})$ & $P$-value \\
\hline Lymph node metastasis $(+/-)$ & $5.75(3.26-10.8)$ & $<0.0001$ & $4.53(2.48-8.83)$ & $<0.0001$ & $4.91(2.2-12.4)$ & $<0.0001$ & $4.21(1.79-11.6)$ & 0.0007 \\
\hline Tumour size $(\geqslant 2 /<2 \mathrm{~cm})$ & $2.99(1.71-5.53)$ & $<0.0001$ & $2.22(1.24-4.19)$ & 0.0064 & $3.97(1.64-11.8)$ & 0.0014 & $2.87(1.16-8.68)$ & 0.021 \\
\hline $\operatorname{PgR}(+/-)$ & $0.41(0.25-069)$ & 0.0006 & & NS & $0.24(0.11-0.51)$ & 0.0002 & & NS \\
\hline Nuclear grade (3/1-2) & $1.94(1.13-3.26)$ & 0.015 & & NS & $0.256(0.19-5.41)$ & 0.0163 & & NS \\
\hline
\end{tabular}

In addition to the application of PLS3 as a sole CTC marker, our approach may also have implications for treatment selection and monitoring. Nottingham Prognostic Index (NPI) has been one of the most studied and recognised prognostic index (Haybittle et al, 1982; Rakha et al, 2008). Our study showed that PLS3 was a significant independent risk factor for survival besides lymph node metastasis and tumour size. Our results did not directly compare the prognostic significance between NPI and PLS3, but PLS3 would be a biomarker of relapse, monitoring and surveillance as well as survival. The present approach may contribute to the selection of high-risk groups of breast cancer patients who require more aggressive systemic therapy to prevent or slow metastatic relapse. In addition, a blood-based marker has the potential for repeated examinations during the course of treatment and after removal of the primary tumour, permitting use in monitoring and for optimising therapeutic strategies.

\section{ACKNOWLEDGEMENTS}

We thank K. Oda, M. Kasagi, S. Kohno, T. Kawano, M. Aoyagi, and A. Andreas for their technical assistance.

This work was supported in part by Japan Society for the Promotion of Science (JSPS) Grant-in-Aid for Scientific Research, grant numbers 20790961, 20659209, 20790960, and 24592005.

\section{CONFLICT OF INTEREST}

The authors declare no conflict of interest.

\section{REFERENCES}

Bartkowiak K, Effenberger KE, Harder S, Andreas A, Buck F, Peter-Katalinic J, Pantel K, Brandt BH (2010) Discovery of a novel unfolded protein response phenotype of cancer stem/progenitor cells from the bone marrow of breast cancer patients. J Proteome Res 9(6): 3158-3168.

Bartkowiak K, Wieczorek M, Buck F, Harder S, Moldenhauer J, Effenberger KE, Pantel K, Peter-Katalinic J, Brandt BH (2009)

Two-dimensional differential gel electrophoresis of a cell line derived from a breast cancer micrometastasis revealed a stem/ progenitor cell protein profile. J Proteome Res 8(4): 2004-2014.

Braun S, Pantel K (2001) Immunocytochemical detection and characterization of individual micrometastatic tumor cells. Methods Mol Med 57: 67-73.

Goldhirsch A, Glick JH, Gelber RD, Coates AS, Thurlimann B, Senn HJ, Panel M (2005) Meeting highlights: international expert consensus on the primary therapy of early breast cancer 2005. Ann Oncol 16(10): 1569-1583.
Haybittle JL, Blamey RW, Elston CW, Johnson J, Doyle PJ, Campbell FC, Nicholson RI, Griffiths K (1982) A prognostic index in primary breast cancer. Br J Cancer 45(3): 361-366.

Iwaya T, Fukagawa T, Suzuki Y, Takahashi Y, Sawada G, Ishibashi M, Kurashige J, Sudo T, Tanaka F, Shibata K, Endo F, Katagiri H, Ishida K, Kume K, Nishizuka S, Iinuma H, Wakabayashi G, Mori M, Sasako M, Mimori K (2013) Contrasting expression patterns of histone mRNA and microRNA 760 in patients with gastric cancer. Clin Cancer Res 19(23): 6438-6449.

Jiang Z, Jones R, Liu JC, Deng T, Robinson T, Chung PE, Wang S, Herschkowitz JI, Egan SE, Perou CM, Zacksenhaus E (2011) RB1 and p53 at the crossroad of EMT and triple-negative breast cancer. Cell Cycle 10(10): 1563-1570.

Kang Y, Pantel K (2013) Tumor cell dissemination: emerging biological insights from animal models and cancer patients. Cancer Cell 23(5): 573-581.

Kosaka Y, Kataoka A, Yamaguchi H, Ueo H, Akiyoshi S, Sengoku N, Kuranami M, Ohno S, Watanabe M, Mimori K, Mori M (2012) Vascular endothelial growth factor receptor-1 mRNA overexpression in peripheral blood as a useful prognostic marker in breast cancer. Breast Cancer Res 14(5): R140.

Li CI, Daling JR, Porter PL, Tang MT, Malone KE (2009) Adjuvant hormonal therapy for breast cancer and risk of hormone receptor-specific subtypes of contralateral breast cancer. Cancer Res 69(17): 6865-6870.

Mimori K, Fukagawa T, Kosaka Y, Ishikawa K, Iwatsuki M, Yokobori T, Hirasaki S, Takatsuno Y, Sakashita H, Ishii H, Sasako M, Mori M (2008a) A large-scale study of MT1-MMP as a marker for isolated tumor cells in peripheral blood and bone marrow in gastric cancer cases. Ann Surg Oncol 15(10): 2934-2942.

Mimori K, Fukagawa T, Kosaka Y, Kita Y, Ishikawa K, Etoh T, Iinuma H, Sasako M, Mori M (2008b) Hematogenous metastasis in gastric cancer requires isolated tumor cells and expression of vascular endothelial growth factor receptor-1. Clin Cancer Res 14(9): 2609-2616.

Mori M, Mimori K, Ueo H, Tsuji K, Shiraishi T, Barnard GF, Sugimachi K, Akiyoshi T (1998) Clinical significance of molecular detection of carcinoma cells in lymph nodes and peripheral blood by reverse transcription-polymerase chain reaction in patients with gastrointestinal or breast carcinomas. J Clin Oncol 16(1): 128-132.

Mori M, Mimori K, Yoshikawa Y, Shibuta K, Utsunomiya T, Sadanaga N, Tanaka F, Matsuyama A, Inoue H, Sugimachi K (2002) Analysis of the gene-expression profile regarding the progression of human gastric carcinoma. Surgery 131(1 Suppl): S39-S47.

Nguyen PL, Taghian AG, Katz MS, Niemierko A, Abi Raad RF, Boon WL, Bellon JR, Wong JS, Smith BL, Harris JR (2008) Breast cancer subtype approximated by estrogen receptor, progesterone receptor, and HER-2 is associated with local and distant recurrence after breast-conserving therapy. J Clin Oncol 26(14): 2373-2378.

Pantel K, Brakenhoff RH, Brandt B (2008) Detection, clinical relevance and specific biological properties of disseminating tumour cells. Nat Rev Cancer 8(5): 329-340.

Polyak K, Weinberg RA (2009) Transitions between epithelial and mesenchymal states: acquisition of malignant and stem cell traits. Nat Rev Cancer 9(4): 265-273. 
Rakha EA, El-Sayed ME, Lee AH, Elston CW, Grainge MJ, Hodi Z, Blamey RW, Ellis IO (2008) Prognostic significance of Nottingham histologic grade in invasive breast carcinoma. J Clin Oncol 26(19): 3153-3158.

Sugimachi K, Yokobori T, Iinuma H, Ueda M, Ueo H, Shinden Y, Eguchi H, Sudo T, Suzuki A, Maehara Y, Mori M, Mimori K (2014) Aberrant expression of plastin-3 via copy number gain induces the epithelialmesenchymal transition in circulating colorectal cancer cells. Ann Surg Oncol 21(11): 3680-3690.

Tam WL, Weinberg RA (2013) The epigenetics of epithelial-mesenchymal plasticity in cancer. Nat Med 19(11): 1438-1449.

Yokobori T, Iinuma H, Shimamura T, Imoto S, Sugimachi K, Ishii H, Iwatsuki M, Ota D, Ohkuma M, Iwaya T, Nishida N, Kogo R, Sudo T, Tanaka F, Shibata K, Toh H, Sato T, Barnard GF, Fukagawa T,

Yamamoto S, Nakanishi H, Sasaki S, Miyano S, Watanabe T, Kuwano H,
Mimori K, Pantel K, Mori M (2013) Plastin3 is a novel marker for circulating tumor cells undergoing the epithelial-mesenchymal transition and is associated with colorectal cancer prognosis. Cancer Res 73(7): 2059-2069.

Zhang L, Riethdorf S, Wu G, Wang T, Yang K, Peng G, Liu J, Pantel K (2012) Meta-analysis of the prognostic value of circulating tumor cells in breast cancer. Clin Cancer Res 18(20): 5701-5710.

This work is published under the standard license to publish agreement. After 12 months the work will become freely available and the license terms will switch to a Creative Commons AttributionNonCommercial-Share Alike 3.0 Unported License.

Supplementary Information accompanies this paper on British Journal of Cancer website (http://www.nature.com/bjc) 